\title{
EL DERECHO A LA TRADUCCIÓN Y LA INTERPRETACIÓN EN EL SISTEMA JURÍ- DICO URUGUAYO
}

\section{THE RIGHT TO TRANSLATION AND INTERPRETATION IN URUGUAY'S LEGAL SYSTEM}

\section{O DIREITO À TRADUÇÃO E INTERPRETAÇÃO NO SISTEMA JURÍDICO URUGUAIO}

María Emilia Miller Genta*

RESUMEN. El presente trabajo explora el derecho humano a la traducción y la interpretación en materia jurídica. Partimos de la inexorable relación entre traducción jurídica y Derecho Comparado para presentar luego el alcance de los derechos a la traducción y la interpretación según se encuentran recogidos en el sistema jurídico uruguayo y en los instrumentos internacionales ratificados por nuestro país.

PALABRAS CLAVE. Traducción. Interpretación. Derechos lingüísticos. Sistemas jurídicos. Derecho Comparado.

ABSTRACT. This paper revolves around the human right to translation and interpretation within a legal context. Our starting point lies on the inevitable nexus between legal translation and Comparative Law. Further, the scope of the rights to translation and interpretation is set forth, both as enshrined in Uruguay's legal system as well as in international instruments ratified by our country.

KEY WORDS. Translation. Interpretation. Language rights. Legal systems. Comparative Law.

RESUMO. Neste trabalho explora-se o direito humano à tradução e interpretação em matéria jurídica. Partimos da inexorável relação entre a tradução jurídica e o Direito Comparado, para assim apresentar o alcance dos direitos à tradução e interpretação segundo se encontram recolhidos no sistema jurídico uruguaio e nos instrumentos internacionais ratificados por nosso país.

PALAVRAS-CHAVE: Tradução. Interpretação. Direitos linguísticos. Sistemas jurídicos. Direito Comparado.

\footnotetext{
* Traductora Pública en idioma inglés y Doctora en Derecho y Ciencias Sociales egresada de la de la Universidad de la República. Correo electrónico: mariaemiliamillergenta@gmail.com
} 


\section{Breves apuntes sobre traducción jurídica y Derecho Comparado}

Decía el constitucionalista uruguayo Héctor Gross Espiell que “...pensar solo en las definiciones que resultan de nuestro peculiar sistema jurídico - creyendo que constituyen un valor universal y único - no solo constituye un error, sino además una peligrosa negación de la positividad y la riqueza de la diversidad de las diferentes culturas humanas". A la luz de esta reflexión, concebimos la traducción jurídica como un ejercicio de Derecho Comparado que permite buscar equivalencias entre instituciones pertenecientes a distintos sistemas jurídicos, a los efectos de trasmitir un mismo mensaje de naturaleza jurídica en otra lengua.

Partiremos de la definición de traducción jurídica que propone la catedrática española Anabel Borja Albi según las funciones de los textos originales: "La traslación de una lengua a otra de los textos que se utilizan en las relaciones entre el poder público y el ciudadano (por ejemplo: denuncias, querellas, exhortos, citaciones, leyes) y también, naturalmente, de los textos empleados para regular las relaciones entre particulares con trascendencia jurídica (que dan lugar a contratos, testamentos o poderes)"”.

En tanto, la reconocida académica chinoaustraliana Deborah Cao plantea que la traducción jurídica refiere a la traducción de textos utilizados en el Derecho o en contextos jurídicos y apunta una clasificación de los textos pasibles de ser traducidos, a saber: (a) textos legislativos, (b) textos judiciales, (c) textos doctrinarios y (d) textos jurídicos privados. Según la autora, la principal fuente de dificultad de la traducción jurídica radica en que involucra sistemas jurídicos distintos, puesto que el Derecho y el lenguaje jurídico se encuentran ligados a una tradición jurídica determinada, como por ejemplo el sistema romano germánico o el anglosajón, entre otros, cada uno con sus particularidades lingüísticas, institucionales, ideológicas, filosóficas y culturales³.

Otra docente española en la materia, Elena Ferrán Larraz, enseña que los obstáculos frente a la traducción jurídica son que el lenguaje jurídico es un lenguaje técnico con una naturaleza específica y que el ordenamiento jurídico es un fenómeno cultural. A partir de un ejemplo concreto, brinda soluciones frente a una institución extranjera desconocida en función de métodos juscomparatistas (esto es, la negación de la institución, la aproximación funcional o analógica y el reconocimiento de la institución extranjera) ${ }^{4}$.

1-GROSS ESPIELL, Héctor. (2000) El lenguaje y el Derecho. Revista del Colegio de Traductores Públicos del Uruguay, $\mathrm{N}^{\circ} 17,2^{\mathrm{a}}$ época, Diciembre de 2000, pp. 14-25.

2-BORJA ALBI, Anabel. (2003) La traducción jurídica: didáctica y aspectos textuales. En: Aproximaciones a la traducción. Centro Virtual Cervantes. Disponible en línea en: https://cvc.cervantes.es/lengua/aproximaciones/borja.htm (Fecha de consulta: 23/02/2020)

3- CAO, Deborah (2009). Translating Law (Topics in Translation $N^{\circ} 33$ ). Multilingual Matters Ltd.

4-FERRÁNZ LARRAZ, Elena (2009). La institución desconocida y la intraducibilidad. Paralelismo entre el Derecho Comparado y la traducción jurídica frente a la intraducibilidad. Disponible en línea: https://www.erudit.org/fr/revues/ 
Siguiendo con esta línea de razonamiento, el profesor español Fernando Prieto Ramos propone que un estudio interdisciplinario de la traducción jurídica necesariamente entrará en contacto con la funcionalidad del Derecho Comparado, en la medida que ofrece herramientas para la interpretación de los textos jurídicos y su análisis contrastivo. La metodología jurídica comparada es, según el autor, particularmente importante a efectos de la traducción jurídica, puesto que comparten el mismo objetivo de desglosar conceptos jurídicos para determinar equivalencias entre diversos sistemas jurídicos. Estos enfoques derivaron en el estudio de la lingüística jurídica o jurilingüística, así como la lingüística jurídica contrastivas.

También en nuestro medio, el profesor emérito de la carrera de Traductorado Público de la Universidad de la República, Roberto Puig, identificó las complejidades de la traducción jurídica en tanto se vincula al Derecho Comparado: "En materia jurídica, la formación del profesional presenta dificultades ajenas a otros campos. En primer lugar, la complejidad conceptual de los textos jurídicos, y en segundo, las diferencias existentes entre los distintos sistemas, especialmente entre los del Derecho angloamericano y el romano-germánico de estas latitudes (que en inglés se conoce como Civil Law).”。

Es en este marco que nos planteamos un estudio del tratamiento de la traducción y la interpretación en el ámbito jurídico según se encuentran recogidas en el ordenamiento jurídico uruguayo y en los instrumentos internacionales que nos resultan aplicables, desde una óptica de derechos humanos que las engloba principalmente dentro de la concepción de derechos lingüísticos ${ }^{7}$, así como también del derecho al acceso a la justicia y al debido proceso.

II. Derecho a la traducción y la interpretación

meta/2009-v54-n2-meta3238/037682ar.pdf (Fecha de consulta: 04/03/2020)

5-PRIETO RAMOS, Fernando (2014). Legal Translation Studies as Interdiscipline: Scope and Evolution. Meta, 59 (2), 260-277. Disponible en línea en: https://doi.org/10.7202/1027475ar (Fecha de consulta: 04/02/2020)

6-PUIG, Roberto (2017). Enseñanza y evaluación de la traducción jurídica. Revista Anales de la Facultad de Ciencias Jurídicas y Sociales. Universidad Nacional de La Plata, Buenos Aires, Argentina. Año 14 /No 47 2017. Disponible en línea en:

http://sedici.unlp.edu.ar/bitstream/handle/10915/66135/Documento_completo.pdfPDFA.pdf?sequence=1\&isAllowe$\mathrm{d}=\mathrm{y}$ (Fecha de consulta: 16/04/2020)

7-Estos derechos comprenden a grandes rasgos los que surgen del artículo 3 de la Declaración Universal de Derechos Lingüísticos de 1996 en la órbita de las Naciones Unidas, a saber: "1. Esta Declaración considera como derechos personales inalienables, ejercibles en cualquier situación, los siguientes: el derecho a ser reconocido como miembro de una comunidad lingüística; el derecho al uso de la lengua en privado y en público; el derecho al uso del propio nombre; el derecho a relacionarse y asociarse con otros miembros de la comunidad lingüística de origen; el derecho a mantener y desarrollar la propia cultura; y el resto de derechos de contenido lingüístico reconocidos en el Pacto Internacional de Derechos Civiles y Políticos de 16 de diciembre de 1966 y en el Pacto Internacional de Derechos Económicos, Sociales y Culturales de la misma fecha. 2. Esta Declaración considera que los derechos colectivos de los grupos lingüísticos, además de los establecidos por sus miembros en el apartado anterior, también pueden incluir, de acuerdo con las puntualizaciones del artículo 2.2: el derecho a la enseñanza de la propia lengua y cultura; el derecho a disponer de servicios culturales; el derecho a una presencia equitativa de la lengua y la cultura del grupo en los medios de comunicación; el derecho a ser atendidos en su lengua en los organismos oficiales y las relaciones socioeconómicas." 
Corresponde en primera instancia distinguir entre traducción e interpretación. La traducción supone producir un texto en una lengua a partir de un texto redactado en otra lengua, mientras que la interpretación implica expresar en una lengua lo que un orador dijo en otra lengua. Por lo tanto, a grandes rasgos, la traducción es escrita y la interpretación es oral.

No encontramos en nuestro medio una definición clara de estos derechos inherentes a la personalidad humana, que ingresan a nuestra Constitución en virtud de los artículos 7, 72 y 332, pero que además se encuentran recogidos en diversos textos legales y reglamentarios del ordenamiento jurídico uruguayo. Tomaremos en cambio, en un ejercicio analógico y a título meramente informativo, las definiciones proporcionadas por la Directiva 2010/64/UE del Parlamento Europeo y del Consejo, específicamente en el ámbito de los procesos penales.

En este sentido, el artículo 2 define el derecho a la interpretación como la facultad de que la persona "que no hable o entienda la lengua del proceso penal se beneficie sin demora de interpretación en el transcurso del proceso penal ante las autoridades de la investigación y judiciales, incluido durante el interrogatorio policial, en todas las vistas judiciales y las audiencias intermedias que sean necesarias". En tanto, el artículo 3 define el derecho a la traducción como la facultad de que la persona "que no entienda la lengua del proceso penal se beneficie, en un plazo razonable, de la traducción escrita de todos los documentos que resultan esenciales para garantizar que esté en condiciones de ejercer el derecho a la defensa y para salvaguardar la equidad del proceso".

Es válido mencionar que la citada directiva hace asimismo hincapié en la formación de los traductores e intérpretes y la calidad de los servicios de traducción e interpretación, así como en la obligación de los Estados miembro de garantizar estos derechos y de incorporar la directiva a sus respectivos Derechos internos. Sobre este punto, debemos agregar también que la Unión Europea en tanto organismo supranacional ha realizado un gran desarrollo en materia de legislación multilingüe y la consecuente traducción jurídica de la normativa europea a todas sus lenguas, incluso con la incorporación de la figura del "jurista lingüista" como profesional experto en Derecho y lenguas.

III. Referencias al derecho a la traducción y la interpretación en el sistema jurídico uruguayo

Si bien la Constitución uruguaya no hace mención a lengua oficial alguna, el artículo 65 del Código General del Proceso dispone que "En todos los actos procesales se utilizará, necesariamente, el idioma castellano". Es así que obtenemos una pauta respecto a la lengua en que deben llevarse a cabo los procesos judiciales. Lo que es más, el segundo inciso del mismo artículo agrega "Cuando deba ser oído quien no lo conozca, el tribunal

8-Directiva 2010/64/UE del Parlamento Europeo y del Consejo de 20 de octubre de 2010 relativa al derecho a interpretación y a traducción en los procesos penales

9-Artículo 65 del Código General del Proceso 
nombrará un intérprete" ${ }^{10}$, lo que constituye una referencia explícita al derecho a la interpretación.

El Código General del Proceso realiza otras dos referencias a la temática que nos convoca. Por un lado, el artículo 72.3 prevé una obligación relativa a los documentos que se incorporen al expediente: "Todo documento redactado en idioma extranjero deberá acompañarse con su correspondiente traducción realizada por traductor público, salvo excepción consagrada por leyes o tratados. Pero cuando se trate de libros o documentos muy extensos, podrá disponerse la traducción solo de aquella parte que interese al proceso"" . Por otra parte, el artículo 39.2 hace lo suyo en lo que respecta a las formalidades que deben reunir los poderes para litigar: "Del poder otorgado en el extranjero se presentará copia de su protocolización, que deberá haber sido legalizada y traducida, si correspondiera" 12 .

La traducción de prueba documental puede tener lugar frente a la necesidad de presentar en juicio documentos redactados en lengua extranjera que acompañen a una demanda o contestación, por ejemplo. Según la materia del proceso, podrán necesitarse traducciones de testimonios de partidas, poderes, certificados notariales, títulos valores, estatutos de sociedades comerciales, contratos, entre otros.

Para estos casos la ley exige una traducción pública para el diligenciamiento de la prueba documental, que consiste en una traducción al español firmada y sellada por traductor público uruguayo, en estricto cumplimiento de las formalidades establecidas. En la traducción constará un cierre en el que el traductor público declara que se trata de una traducción verdadera y completa.

Asimismo, para que la traducción oficial tenga validez, los documentos públicos expedidos en el extranjero deberán ser debidamente legalizados o bien deberán contar con Apostilla si el documento proviene de un Estado signatario del Convenio de La Haya de 1961 (artículo 72.2 del Código General del Proceso). Es importante destacar que la traducción oficial de documentos redactados en lengua extranjera habilita que desplieguen efectos jurídicos en nuestro país, de manera que facilita la aplicación del Derecho extranjero.

No obstante, como es sabido, no todos los medios de prueba amparados por nuestra legislación procesal son documentales. En este sentido, debemos recurrir a la interpretación para todos los medios de prueba que suponen una declaración oral de parte de una persona física. Es así que podrá necesitarse un intérprete para un testigo que no hable español en una prueba testimonial o para una parte que no hable español en una declaración de parte, por ejemplo.

En consecuencia, variados actos procesales requieren la asistencia de un traductor o un intérprete, necesariamente un profesional de la lengua, para verter en español lo que una 
parte o un testigo aporten ante el juez en lengua extranjera.

En el listado de peritos del Poder Judicial figuran traductores públicos de inglés, portugués, francés, italiano y alemán, que son las cinco lenguas en las que se dicta la carrera de Traductorado Público en la Facultad de Derecho de la Universidad de la República. Asimismo, en la actualidad tenemos idóneos inscritos como peritos en árabe, chino y coreano $^{13}$. Es idónea aquella persona que manifieste un conocimiento experto de alguna lengua fuera de las previstas en la carrera de Traductorado Público.

En forma análoga, nuestro sistema jurídico ampara el derecho a la traducción y la interpretación también en materia procesal penal. Es así que el artículo 108 del Código del Proceso Penal establece que "Los actos procesales deberán cumplirse en idioma español. La declaración de personas que ignoren el idioma español, de sordomudos que no sepan darse a entender por escrito o lenguaje gestual y los documentos o grabaciones en lengua distinta, o en otra forma de transmisión del conocimiento, deberán ser traducidos o interpretados, según corresponda" ${ }^{14}$. Específicamente en relación con la prueba documental, el artículo 175.1 del mismo código dispone: "Todo documento redactado en idioma distinto al español, deberá estar traducido por un traductor público para ser incorporado al proceso" 15 .

En lo que respecta al Código Civil, encontramos una referencia expresa al derecho a la traducción en materia testamentaria. Es el caso del artículo 799, a saber: "Quien no conozca el castellano, pero se exprese claramente en otro idioma y lo escriba, podrá otorgar testamento abierto en la siguiente forma: Presentará al Escribano el pliego que contenga su testamento, en el papel de la clase que corresponda al protocolo, firmado de su puño y letra, cuya presentación la hará ante dos intérpretes y tres testigos que conozcan su idioma. Los intérpretes harán su traducción fiel; y transmitida al testador en presencia de los testigos y del Escribano, si aquél no tuviese observación que hacer, la suscribirá juntamente con los traductores y testigos. El Escribano levantará, a continuación de la traducción, acta de haber presenciado lo ocurrido, la que será firmada por los concurrentes y después de rubricadas por el Escribano cada una de las fojas del testamento original y traducción, lo incorporará todo al Registro de Protocolizaciones" ${ }^{\prime 16}$.

El sistema jurídico uruguayo también prevé el decreto-ley $\mathrm{N}^{\circ} 15.441$, "Fijación de normas para legalizar documentos extranjeros", que refiere a la traducción de documentos en los artículos 3 y 5, pero que puntualmente en su artículo 6 dispone lo siguiente: "Las sentencias y los laudos homologados, dictados en asuntos civiles, comerciales, laborales, penales y administrativos, las escrituras públicas y demás documentos otorgados por las

13-Registro Único de Peritos Habilitados, actualizado al 19 de diciembre de 2019. Disponible en línea en: http://www. poderjudicial.gub.uy/servicios-en-linea/peritos-habilitados.html (Fecha de consulta: 16/04/2020)

14-Artículo 108 del Código de Proceso Penal

15-Artículo 175.1 del Código de Proceso Penal

16-Artículo 799 del Código Civil 
autoridades públicas competentes de los estados extranjeros o provenientes de Organizaciones Internacionales, los exhortos o cartas rogatorias y documentos privados no redactados en español para surtir efecto en la República, deberán ser traducidos por traductor público nacional" "17. A este mandato se incorporan también los requisitos de legalización o apostillado, según corresponda.

Lo que es más, contamos con la Ley de Registros Públicos $\mathrm{N}^{\circ} 16.871$, que nos informa acerca del derecho a la traducción en el caso de poderes otorgados en el extranjero y de documentos extranjeros en general. Así, el artículo 49 subraya: "Cuando la parte actúe por poder otorgado en el extranjero y para los actos cuya inscripción fuere obligatoria, deberá acompañarse el poder, debidamente legalizado y con traducción pública si correspondiere" ${ }_{18}$.

En tanto, el artículo 91 de la misma ley indica: "El documento público o privado proveniente del extranjero deberá sujetarse a los siguientes requisitos previos: 1) Si estuviere en otro idioma deberá estar traducido al idioma español por traductor público nacional. Si viniere traducido de origen un traductor público nacional certificará la correspondencia de la traducción con el original. 2) Legalizarse en forma. 3) Tratándose de bienes inmuebles ubicados en el país deberán protocolizarse el documento y su traducción. La protocolización tendrá carácter de matriz a los efectos previstos por los artículos 1591 y siguientes del Código Civil"19, por lo que no solamente hace referencia a la traducción pública de los documentos extranjeros, sino también al certificado de concordancia expedido por traductor público uruguayo en relación con aquellos documentos que llegan de origen en lengua extranjera con versión española anexa.

Tras analizar los cuerpos legislativos pertinentes, corresponde en este punto el estudio de los actos reglamentarios. En este sentido, el Reglamento Notarial aprobado por acordada de la Suprema Corte de Justicia $N^{\circ} 7533$ recoge el derecho a la traducción y la interpretación en función de las obligaciones impuestas a los Escribanos Públicos para la protocolización, la escrituración y la inscripción de los actos jurídicos.

A este respecto, adquieren relevancia el artículo 91 ("No deben protocolizarse los documentos: provenientes del extranjero, sin que hayan sido legalizados y traducidos, si corresponde" ${ }^{20}$ ), el artículo 92 ("Para protocolizar documentos no redactados en castellano, sin perjuicio de las excepciones dispuestas por ley, es necesario que sean previamente traducidos a este idioma por un traductor público nacional y, si no lo hubiere, por dos intérpretes, que comparecerán ante el Escribano en el acto de solicitarse la protocolización del documento y firmarán el acta respectiva, responsabilizándose de la traducción””, el 
artículo 93 ("Cuando el documento redactado en otro idioma viene acompañado de su traducción al español realizada en el país de origen, un traductor público nacional certificará la correspondencia de la traducción con el original, expidiendo un certificado de concordancia, el que junto con el documento y su traducción se incorporarán al Registro de Protocolizaciones"22) y el artículo 159 ("Cuando el otorgante no conoce el idioma castellano, debe ser asistido por un intérprete, quien le leerá la escritura en el idioma que aquél expresare hablar y entender y por medio del cual prestará su asentimiento. En la escritura, el otorgante, por medio del intérprete, manifestará sus datos individualizantes, declarará no conocer el idioma castellano pero sí su propio idioma, solicitará a dicho intérprete que le lea la escritura en el idioma que conoce y se dejará constancia de la doble lectura y de la forma especial de otorgamiento adoptada. Se prescindirá del intérprete cuando el Escribano conozca el idioma del otorgante, debiendo, después de la lectura en castellano, leer la escritura también en el referido idioma, de todo lo cual se hará mención”"23).

IV. Referencias al derecho a la traducción y la interpretación en instrumentos internacionales

El derecho a la traducción y la interpretación también se encuentra plasmado en instrumentos internacionales ratificados por Uruguay, lo que nos brinda una pauta acerca de las exigencias con que nuestro país debe cumplir en cuanto a su efectividad y su reconocimiento normativo.

A nivel regional, encontramos en el ámbito del Mercosur una exención a este derecho prevista en el "Acuerdo sobre exención de traducción de documentos administrativos para efectos de inmigración". Esta exención rige exclusivamente para los pasaportes, documentos de identidad, testimonios de partidas de nacimiento o de matrimonio y los certificados de antecedentes penales que se presenten "a efectos de trámites migratorios referentes a solicitud de visa, renovación de plazo de estadía y concesión de permanencia"24, y en nuestro país entró en vigor en el año 2007.

En el ámbito interamericano, la Convención Interamericana sobre Prueba e Información acerca del Derecho Extranjero expone en el inciso final de su artículo 5 que: "Las solicitudes serán redactadas en el idioma oficial del Estado requerido o serán acompañadas de una traducción a dicho idioma" ${ }^{25}$. Lo que es más, el artículo 9 de la Convención Interamericana sobre el Régimen Legal de Poderes dispone: "Se traducirán al idioma oficial del Estado de su ejercicio los poderes otorgados en idioma distinto" ${ }_{26}$.

La Convención Interamericana sobre Eficacia Extraterritorial de las Sentencias y Laudos Arbitrales Extranjeros dispone en el artículo 2 que las sentencias, laudos arbitrales, reso-

22- Artículo 93 de la Acordada $N^{\circ} 7533$

23- Artículo 159 de la Acordada $\mathrm{N}^{\circ} 7533$

24-Artículo 1 del Acuerdo sobre exención de traducción de documentos administrativos para efectos de inmigración

25-Artículo 5 de la Convención Interamericana sobre Prueba e Información acerca del Derecho Extranjero

26-Artículo 9 de la Convención Interamericana sobre el Régimen Legal de Poderes 
luciones jurisdiccionales u otros documentos extranjeros deberán constar "debidamente traducidos al idioma oficial del Estado donde deban surtir efecto" ${ }^{27}$.

La Convención Interamericana de Derechos Humanos o Pacto de San José de Costa Rica de 1969, reconoce expresamente y jerarquiza el derecho a la traducción y la interpretación en los procesos penales en el literal a) del numeral 2 del artículo 8 bajo el acápite "Garantías judiciales", en los siguientes términos: "Toda persona inculpada de delito tiene derecho a que se presuma su inocencia mientras no se establezca legalmente su culpabilidad. Durante el proceso, toda persona tiene derecho, en plena igualdad, a las siguientes garantías mínimas: a) derecho del inculpado de ser asistido gratuitamente por el traductor o intérprete, si no comprende o no habla el idioma del juzgado o tribunal..."”28 Lo que es más, el Pacto Internacional de Derechos Civiles y Políticos de 1966, en la esfera de las Naciones Unidas, dispone en el numeral 3 de su artículo 14 que: " Durante el proceso, toda persona acusada de un delito tendrá derecho, en plena igualdad, a las siguientes garantías mínimas: a) A ser informada sin demora, en un idioma que comprenda y en forma detallada, de la naturaleza y causas de la acusación formulada contra ella..." y “...f) A ser asistida gratuitamente por un intérprete, si no comprende o no habla el idioma empleado en el tribunal..." ${ }_{29}$

V. Conclusiones

La traducción y la interpretación en el ámbito jurídico encuentran en el Derecho Comparado un aliado a la hora de desarrollar la tarea de extrapolar conceptos jurídicos entre sistemas jurídicos diversos. Los avances en cuanto a la definición del derecho a la traducción y la interpretación consumados por la Unión Europea, así como el tratamiento de la legislación multilingüe, resultan alentadores, y nos interpelan a reflexionar acerca del estado de la materia en el ámbito interamericano, particularmente en lo que respecta a los derechos lingüísticos de las minorías indígenas en América Latina.

El derecho a la traducción y a la interpretación no se encuentra definido en forma expresa en el ordenamiento jurídico uruguayo ni tampoco surge explícitamente de la Constitución de la República. No obstante, el legislador uruguayo lo tuvo en cuenta como garantía para el otorgamiento de actos jurídicos y la celebración de procesos judiciales, y por tanto se encuentra recogido en el Código General del Proceso, el Código de Proceso Penal, el Código Civil, la Ley de Fijación de Normas para Legalizar Documentos Extranjeros (15.441), la Ley de Registros Públicos (16.871) y el Reglamento Notarial (Acordada 7533).

En el plano internacional, el derecho a la traducción y la interpretación se encuentra exonerado para determinados documentos a escala del Mercosur, con fundamento en la agili-

27-Artículo 2 de la Convención Interamericana sobre Eficacia Extraterritorial de las Sentencias y Laudos Arbitrales

Extranjeros

28-Artículo 8 de la Convención Interamericana de Derechos Humanos

29- Artículo 14 del Pacto Internacional de Derechos Civiles y Políticos 
zación de los trámites migratorios, mientras que en el ámbito interamericano se reconoce expresamente a efectos procesales en el Pacto de San José de Costa Rica. Asimismo, se encuentra recogido en la Convención Interamericana sobre Prueba e Información acerca del Derecho Extranjero, la Convención Interamericana sobre el Régimen Legal de Poderes, la Convención Interamericana sobre Eficacia Extraterritorial de las Sentencias y Laudos Arbitrales Extranjeros y el Pacto de Derechos Civiles y Políticos.

En suma, tanto la traducción de documentos redactados en lengua extranjera como la interpretación del discurso de aquellas personas que no conocen el idioma español, son servicios lingüísticos esenciales para la administración de justicia, que garantizan la seguridad jurídica y democratizan el pleno ejercicio de los derechos y las obligaciones.

Bibliografía

BORJA ALBI, Anabel. (2003) La traducción jurídica: didáctica y aspectos textuales. En: Aproximaciones a la traducción. Centro Virtual Cervantes. Disponible en línea: https:// cvc.cervantes.es/lengua/aproximaciones/borja.htm (Fecha de consulta: 23/02/2020) CAO, Deborah (2009). Translating Law (Topics in Translation $\mathrm{N}^{\circ} 33$ ). Multilingual Matters Ltd.

FERRÁNZ LARRAZ, Elena (2009). La institución desconocida y la intraducibilidad. Paralelismo entre el Derecho Comparado y la traducción jurídica frente a la intraducibilidad. Disponible en línea en:

https:/www.erudit.org/fr/revues/meta/2009-v54-n2-meta3238/037682ar.pdf (Fecha de consulta: 04/03/2020)

GROSS ESPIELL, Héctor. (2000) El lenguaje y el Derecho. Revista del Colegio de Traductores Públicos del Uruguay, N 17, 2ª época, Diciembre de 2000.

PRIETO RAMOS, Fernando (2014). Legal Translation Studies as Interdiscipline: Scope and Evolution. Meta, 59 (2), 260-277. Disponible en línea en: https://doi.org/10.7202/1027475ar (Fecha de consulta: 04/02/2020)

PUIG, Roberto (2017). Enseñanza y evaluación de la traducción jurídica. Revista Anales de la Facultad de Ciencias Jurídicas y Sociales. Universidad Nacional de La Plata, Buenos Aires, Argentina. Año 14 / No 47 2017. Disponible en línea en:

http://sedici.unlp.edu.ar/bitstream/handle/10915/66135/Documento_completo.pdfPDFA.pdf? sequence=1\&isAllowed=y (Fecha de consulta: 16/04/2020)

Compilados normativos

"Normativa relativa a la traducción de documentos extranjeros. Intervención del Traductor Público nacional.” presentado en la XII Jornada Notarial Iberoamericana, Noviembre de 2006, Punta del Este, Uruguay. Disponible en línea:https://www.colegiotraductores. org.uy/Traduccion $\% 20 \mathrm{de} \% 20$ documentos $\% 20$ extranjeros\%20-\%20Normativa.pdf (Fe- 